\title{
Influence of high-frequency microwave radiation on montmorillonite structure parameters
}

\section{(Influência da radiação de micro-ondas de alta frequência nos parâmetros estruturais da montmorilonita)}

\author{
A. G. Chetverikova ${ }^{1 *}$, M. M. Filyak ${ }^{1}$, O. N. Kanygina ${ }^{1}$ \\ ${ }^{I}$ Orenburg State University, Orenburg, Russia
}

\begin{abstract}
Influence of microwave radiation on structure changes of montmorillonite particles was studied on a montmorillonite clay sample. Multi-scale long-range processes were induced in the nature-occurring aluminosilicates by microwave radiation of low and medium power $(2.45 \mathrm{~Hz}, 750 \mathrm{~W}, 10 \mathrm{~min})$. Powdered samples treated with microwave radiation demonstrated reduction of the relative intensity of diffraction peaks and reduction of interplanar spacing of montmorillonite lattice $\left(\mathrm{d}_{001}{ }^{*}\right.$ from 1.220 to $0.945 \mathrm{~nm}, \mathrm{~d}_{001}$ from 0.642 to $0.627 \mathrm{~nm}, \mathrm{~d}_{002}$ from 0.318 to $0.314 \mathrm{~nm}$ and $\mathrm{d}_{003}$ from 0.214 to $0.213 \mathrm{~nm}$ ). The effect was due to extraction of water molecules contained in three-layer packages. Water extraction occurred stepwise with the temperature rise which pointed on long-range processes with a delayed effect. Heating of powdered samples up to $200{ }^{\circ} \mathrm{C}$ resulted in the destruction of half of the montmorillonite lattice volume; at $400{ }^{\circ} \mathrm{C}$ about $70 \%$ of the lattice was destroyed. Fragments of lattice cells formed agglomerates via two-step mechanism. The degree of agglomeration was proportional to the montmorillonite sample amorphicity.
\end{abstract}

Keywords: structure, morphology, microwave, montmorillonite, X-ray diffraction analysis, interplanar distance.

\section{Resumo}

A influência da radiação micro-ondas nas alterações estruturais das partículas de montmorilonita foi estudada em uma amostra de argila montmorilonítica. Processos de longo alcance em múltiplas escalas foram induzidos nos aluminossilicatos naturais por radiação de micro-ondas de baixa e média potência $(2,45 \mathrm{~Hz}, 750 \mathrm{~W}, 10 \mathrm{~min})$. Amostras em pó tratadas com radiação microondas demonstraram redução da intensidade relativa dos picos de difração e redução do espaçamento interplanar da rede de montmorilonita ( $d_{001} *$ de 1,220 a $0,945 \mathrm{~nm}, d_{001}$ de 0,642 a 0,627 nm, $d_{002}$ de 0,318 a 0,314 nm e $d_{003}$ de 0,214 a 0,213 nm). O efeito foi devido à extração de moléculas de água contidas em empacotamentos de três camadas. A extração de água ocorreu em etapas com o aumento da temperatura, indicando processos de longo alcance com efeito retardado. $O$ aquecimento das amostras em pó até $200{ }^{\circ} \mathrm{C}$ resultou na destruição de metade do volume da rede da montmorilonita; a $400{ }^{\circ} \mathrm{C}$ cerca de $70 \%$ da rede foi destruída. Fragmentos de células da rede formaram aglomerados por meio de um mecanismo de duas etapas. O grau de aglomeração foi proporcional à amorficidade da amostra de montmorilonita.

Palavras-chave: estrutura, morfologia, micro-ondas, montmorilonita, difração de raios $X$, distância interplanar.

\section{INTRODUCTION}

In the last 20 years, opportunities and results of microwave radiation application for the invention of new technologies and syntheses of new ceramic materials were actively studied in all scientific centers. In nature-occurring aluminosilicates external influence can induce multi-scale phenomena both at meso- and micro-levels related to selforganizing processes in dissipative structures. Study of laws that drive structure formation in minerals treated with microwave radiation that account for effects taking place at all spatial scales is one of the most important problems of physics and materials science. It is widely accepted that high-frequency electromagnetic field treatment of inorganic compounds is one of the perspective methods of compound

*KR-727@mail.ru

Dhttps://orcid.org/0000-0002-7045-3588 modifications [1-3]. We believe that structural changes in nature-occurring materials, namely, in aluminosilicates that are induced by microwave radiation treatment deserve more detailed expertise. Empirical and theoretical studies of highfrequency electromagnetic field influence on aluminosilicate materials (clays) significantly expanded both spectrum and quality of raw products for functional ceramics. Nonmetallic feeds are highlighted among the other raw products, as they have the shortest time span between a deposit discovery and a market entry of a ready product. At the same time laws driving effects induced by microwave radiation treatment of nature-occurring clays containing impurities and foreign elements are extremely complicated and well-understood for very few special cases. It was shown that clay materials subjected to microwave radiation form nano-scale particles and increase the volume of the response surface $[4,5]$. The adsorption capacity of a material is also altered together with the density of water-soluble substances and some other quality characteristics are improved. Various fundamental 
problems are usually encountered when sintering materials by direct microwave heating. Most of the research on material processing by microwaves is based on conventional low-frequency $(2.45 \mathrm{GHz})$ microwave applicators. However, such applicators do not couple microwave power efficiently to many ceramics at room temperature, and poor microwave absorption characteristics make initial heating difficult [5].

Montmorillonite ore with montmorillonite clay is of our main interest among the other perspective raw materials suitable for new functional materials synthesis. Montmorillonite particles are natural two-dimensional structure-sensitive nanoparticles. Their characteristic spatial scale (less than $1 \mu \mathrm{m}$ ) is significantly smaller than the kaolinite particles size, while the particles themselves resemble rough shape hexagonal plates and have a tendency to aggregation. Essentially, these nature-occurring nanoparticles have a high perspective for the realization of various types of structure evolutions [6]. As montmorillonite samples are unsuitable for optical methods study, X-ray diffraction analysis remains one of the most used study methods. Moreover, Worasith et al. [7] propose to study the quality of nonmetallic feed from various land deposits via electron paramagnetic resonance (EPR). Belchinskaya et al. [8] studied effects induced by 4 min long microwave treatment of montmorillonite clay and discovered a destruction effect enhancing adsorption features of the particles, while the phase composition remains almost unaffected. Barrer [6] studied adsorption water in montmorillonite lattice and interplanar or crystal water which form three main types of bond in the ionhydrate montmorillonite complex. Hydroxyl bond is formed via donor-acceptor mechanism between a hydrogen atom of a water molecule and an oxygen atom of the tetrahedral lattice; coordinate bond is formed between water molecules and off-layer cations. The third type of bounds, hydrogen bonds, which are the weakest bonds, are formed between water molecules of an ion-hydrate layer in the basal plane of montmorillonite particles. In [9], it was established that microwave radiation treatment leads to a reduction of the interplanar distance $\mathrm{d}_{001}$ by $0.20 \mathrm{~nm}$ due to degradation.

Existence of three endothermic effects which are due to extraction of water of various types during the traditional ceramic burning points indicates the presence of complex interactions between montmorillonite particles and water. According to derivatography data [10], the first endothermic effect, which takes place between 50 and $200{ }^{\circ} \mathrm{C}$, corresponds to the extraction of water adsorbed in basal layers of montmorillonite. The second endothermic effect $\left(560-680{ }^{\circ} \mathrm{C}\right.$ ) corresponds to the extraction of hydroxyl water from montmorillonite lattice. The third effect $\left(800-890{ }^{\circ} \mathrm{C}\right)$ corresponds to the destruction of montmorillonite lattice and transition to an amorphous state. Bel'chinskaya et al. [10] show advantages of high-frequency microwave field treatment of montmorillonite, as it allows one to increase adsorption capacity by more than 5 times, while the treatment time is reduced by 15 times. The results agree with the general expectation of significant changes induced by microwave radiation in aluminosilicate particles. In case of multi-component systems, such as nature-occurring clays, effects of microwave radiation influence are uncontrollable, as they are affected by multiple processes taking place in the material. Therefore it is required to gather a large array of data about changes induced by electromagnetic field treatment, as it may provide a certain way to increase control over such processes. The main goal of this paper is to study effects induced in montmorillonite clay particles via microwave radiation treatment, in particular, to study structural changes induced in montmorillonite particles. In the article, the timeline of montmorillonite lattice destruction induced by microwave treatment is presented for the first time.

\section{EXPERIMENTAL METHODOLOGY}

Orenburg region (Russia) holds huge deposits of clay, according to [11] the overall mass of the deposits exceeds 90000 thousands of tons. The clay of the south Ural, especially montmorillonite containing clay, is insufficiently studied as a raw product for functional ceramics, as chemical and physical properties of montmorillonite minerals strongly depend on their formation conditions. In the main formula $\mathrm{Al}_{2} \mathrm{O}_{3} \cdot 4 \mathrm{SiO}_{2} \cdot \mathrm{H}_{2} \mathrm{O}$. $\mathrm{nH}_{2} \mathrm{O}$, where $\mathrm{nH}_{2} \mathrm{O}$ denotes the amount of water, the coefficient $\mathrm{n}$ is the index describing the amount of water containing in the lattice, the swelling properties, and the increase of volume of the dispersal system [6]. The main sample used in the study was a clay with the following chemical composition: $57.46 \%$ $\mathrm{SiO}_{2} ; 4.90 \% \mathrm{Fe}_{2} \mathrm{O}_{3} ; 0.53 \% \mathrm{TiO}_{2} ; 11.00 \% \mathrm{Al}_{2} \mathrm{O}_{3} ; 8.21 \% \mathrm{CaO}$; $2.93 \% \mathrm{MgO} ; 2.04 \% \mathrm{Na}_{2} \mathrm{O} ; 3.04 \% \mathrm{~K}_{2} \mathrm{O}$; and ignition loss was 9.61\% [12]. After mechanical cleaning (dispersion on a sieve with aperture of $160 \mu \mathrm{m}), 50 \%$ of the total volume of the powdered sample was composed of montmorillonite particles. In Table I, the main phase composition of the cleaned clay sample in the initial state is given (sample P0).

Table I - Phase composition of the original sample [13].

[Tabela I - Composição de fases da amostra original [13].]

\begin{tabular}{cccc}
\hline Phase & Formula & Crystal structure & Composition (vol\%) \\
\hline Montmorillonite & $\left(\mathrm{Al}_{2}[\mathrm{OH}]_{2}\left[\mathrm{Si}_{4} \mathrm{O}_{10}\right]\right) \cdot \mathrm{mH}_{2} \mathrm{O}$ & Monoclinic & 50 \\
$\alpha$-tridymite & $\mathrm{SiO}_{2}$ & Hexagonal & 15 \\
$\beta$-quartz & $\mathrm{SiO}_{2}$ & Trigonal & 5 \\
Corundum & $\alpha-\mathrm{Al}_{2} \mathrm{O}_{3}$ & Trigonal & 10 \\
Aluminosilicate & $\mathrm{Al}_{2} \mathrm{O}_{3}-\mathrm{SiO}_{2}$ & Triclinic & 10 \\
Iron oxides & $\mathrm{Fe}_{2} \mathrm{O}_{3}, \mathrm{Fe}_{3} \mathrm{O}_{4}, \mathrm{FeO}$ & Rhombic, cubic & 10 \\
\hline
\end{tabular}


The original batch of powdered sample was subjected to microwave treatment by a field with a nominal power of $750 \mathrm{~W}$ for $10 \mathrm{~min}$ in air and humid medium. The sample heating consumed $75 \%$ of power. The source of the microwave field was a magnetron-based generator producing radiation with frequency of $2.45 \mathrm{GHz}$. All samples were placed on a revolving plate for the sake of uniform heating. Microwaves are electromagnetic waves in the frequency band of 300 $\mathrm{MHz}$ to $300 \mathrm{GHz}$, which corresponds to a wavelength range of $1 \mathrm{~m}$ to $1 \mathrm{~mm}$. Typical frequencies for materials processing are $915 \mathrm{MHz}, 2.45,5.8,22.00,24.12,28$ and 60 $\mathrm{GHz}$, but only $915 \mathrm{MHz}$ and $2.45 \mathrm{GHz}$ are widely used. The advantages of higher frequencies are more uniform electric field distribution in the cavity and higher power dissipated in dielectric materials. However, microwave apparatus is available on a very limited basis and at high-cost [5]. The working space volume was $25 \mathrm{~L}$; all samples were placed on a revolving plate to average heating conditions. In the first case (P1), the sample was placed as $1 \mathrm{~cm}$ thick powder layer in a ditch with area of $9 \mathrm{~cm}^{2}$ and was treated in air medium. In the second case (P2), the sample was treated in a humid medium (partial pressure of evaporated water was increased by 2 times due to water evaporation from an open vessel placed inside the working space of the heater). The batch of sample P3 treated in air medium was formed with a uniform plastic mixture consisting of the same clay particles and mixing water (10\% of the overall mass) with $\mathrm{pH}$ 7. These samples had cylindrical shape with radius of 3 $\mathrm{cm}$ and height of $1 \mathrm{~cm}$.

Mass of samples was measured before and after microwave treatment via analytic balance and it was found that the initial mass of all samples varied about $30.00 \pm 0.01$ g. The temperature of samples after the radiation treatment was measured with an infrared pyrometer (ADA, TemPro 900) with a measurement error of $1.5 \%$ in the range between 0 and $900{ }^{\circ} \mathrm{C}$ and response time of $0.5 \mathrm{~s}$. EPR spectra of clay samples were measured with portable automatic EPR spectrometer (Adani, CMS8400) at room and nitrogen temperature. Conditions of EPR spectra measurements were: frequency of $9.86 \mathrm{GHz}$, magnetic field of 1-7 kOe, modulated to frequency of $100 \mathrm{kHz}$ and amplitude of 6 G. X-ray diffraction patterns, in accordance with [14], were obtained with diffractometers MD-10 (Radicon) and DRON-3M using monochromatic chrome radiation. Two diffractograms were taken for each sample: 1) via MD-10 with the scan rate of $1 \% \mathrm{~min}$ in the $2 \theta$ angle range from $10^{\circ}$ to $120^{\circ}$; and 2) via DROM-3M with the scanning rate of
$1 / 8 \%$ min in the angle range from $10^{\circ}$ to $60^{\circ}$ and the results were obtained in a digital form. The standard deviation of diffraction peak coordinates did not exceed $0.02^{\circ}$. Crystal phases of $\mathrm{SiO}_{2}$ and $\mathrm{Al}_{2} \mathrm{O}_{3}$ with a clean spectrum were used as the reference standard. Diffractogram decoding was performed in accordance with the standard methods. Volume content of crystal phases was estimated via summation of diffraction peak intensities defined with centers of balance. Initial diffractograms reading was performed with the usage of well-known techniques, software application LookPDF, and International Centre for Diffraction Data (ICDD) database.

\section{RESULTS AND DISCUSSION}

During microwave treating, the heat was generated in the whole volume of a sample due to interaction between microwave radiation and atoms, ions, and molecules of the clay material which possessed low absorption factor at frequency of $2.45 \mathrm{GHz}$. Clay materials with a significant amount of $\mathrm{SiO}_{2}$ and $\mathrm{Al}_{2} \mathrm{O}_{3}$ are transparent for microwave radiation at the normal temperature, but the absorption coefficient can be increased by the water component of the clay [3]. In the performed experiments, samples were exposed to the microwave radiation for an equal time interval but heated to different temperatures. The sample that was heated in an aerial environment $(\mathrm{P} 1)$ reached $200^{\circ} \mathrm{C}$; the sample heated in a humid environment $(\mathrm{P} 2)$ reached $400^{\circ} \mathrm{C}$, as well as the sample P3. These results pointed to the difference in structure formations in various samples. This was also indirectly confirmed by the sample mass loss. The heating temperature, which is defined by properties of microwave radiation treatment, significantly affects structure changes; the general parameters are presented in Table II.

Water contained in minerals can be subjected to various classifications. We believe that for montmorillonite samples one should classify water on three components: adsorption, interplanar, and crystallization water [14-16]. Adsorption water molecules are situated at the surface of crystal particles and can be extracted easily via heating. Mass loss of sample P1 $(1.5 \%)$ can be attributed to that case. Increase of sample P2 mass loss (1.8\%) may be related to partial removal of interplanar and crystal water. It is known [14] that during resistance heating in temperature interval from 50 to $200{ }^{\circ} \mathrm{C}$ the first endothermic effect takes place due to extraction of montmorillonite adsorbed water. Interplanar water molecules are situated between neutral layers of the

Table II - Parameters of changes induced by microwave radiation treatment.

[Tabela II - Parâmetros das alterações induzidas pelo tratamento com radiação de micro-ondas.]

\begin{tabular}{lcccc}
\hline Index & P0 & P1 & P2 & P3 \\
\hline Heating temperature, $\mathrm{T}\left({ }^{\circ} \mathrm{C}\right)$ & 20 & 200 & 400 & 400 \\
Mass loss, dm/m $(\%)$ & 0 & 1.5 & 1.8 & 12 \\
Volume content of crystal phases, $\Sigma \mathrm{I}(\%)$ & 100 & 75 & 60 & 60 \\
Volume content of crystal montmorillonite, $\mathrm{I}_{\text {mont }}(\%)$ & 50 & 40 & 30 & 40 \\
\hline
\end{tabular}


lattice. Crystal water occupies specific regions in the lattice, so its extraction is accompanied with a partial lattice alteration or complete destruction of the mineral structure. The same reasons can account for sample P3 mass loss (12\%), which contained $10 \%$ of water in the initial state. Extraction of adsorption, interplanar, and crystal water molecules caused by microwave treatment is accompanied by amorphization of clay minerals, which results in a reduction of the overall intensity of X-ray diffraction pattern maximums. Adsorbed water molecules are easily removed from the surface of particles via microwave treatment. Crystal modification decay timeline of the original samples P1, P2, and P3 induced by microwave treatment showed that in the general case the sample temperature was the main factor affecting amorphization. Increase of the temperature from 200 to $400{ }^{\circ} \mathrm{C}$ reduced the portion of crystal phases by $15 \%$. The destruction process itself was defined by the temperature, microwave treatment conditions, and microstructure state of aluminosilicates in a complex way. This question requires a separate special investigation. Diffraction patterns of powdered samples P0, P1, and P2 (Figs. 1a to 1c) and humid ceramic mixture P4 (Fig. 1d) had different positions and intensities of diffraction peaks. The total amount of crystal modifications reduced with the increase of the heating temperature, as montmorillonite lattice was destroyed.

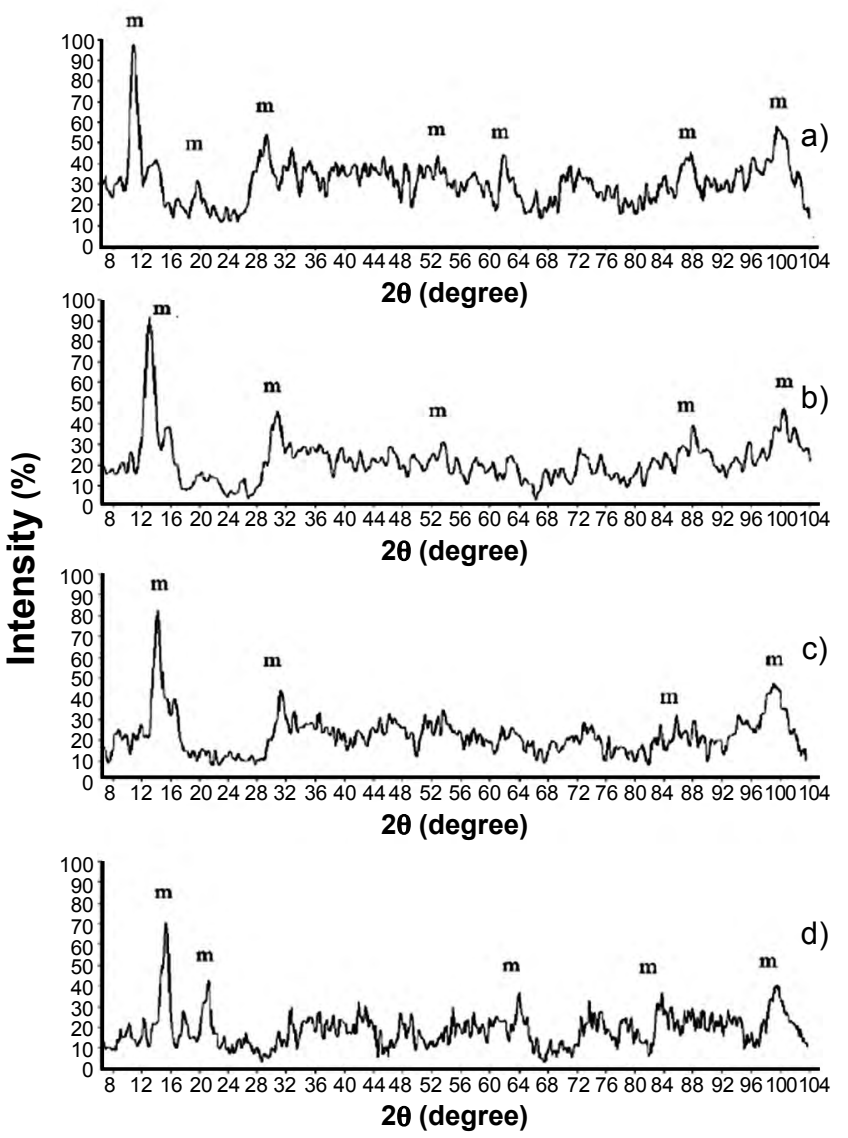

Figure 1: X-ray diffraction patterns of four powdered samples of natural clay: a) P0; b) P1; c) P2; and d) P3.

[Figura 1: Difratogramas de raios $X$ de quatro amostras em pó de argila natural: a) $\mathrm{PO}$; b) $\mathrm{P} 1$; c) $\mathrm{P} 2$; e d) P3.]
Definition of the phase composition of complex heterogeneous systems, such as nature-occurring clays, is a complicated problem that may not be solved uniquely. Wavelet analysis of the initial diffractograms provided data on positions of diffraction peaks and helped to resolve the multiplet peaks. We obtained wavelet-spectrum which was interpreted with the use of local extremum lines, skeletons [13], which are presented in Fig. 2. Wavelet-transformation is less vulnerable for false peak detections, as peaks are searched via analysis of the wavelet-coefficients, not the original dataset [17]. Such a method shows a high sensitivity for low-intensity overlapping peaks. Wavelet-analysis combined with the traditional method of diffractogram decoding provided us with what we believe was the most comprehensive data set, which are presented in Table III. Microwave treatment of powdered samples resulted in the reduction of both montmorillonite lattice interplanar distance and relative diffractogram peak intensity for samples P0, $\mathrm{P} 1$, and $\mathrm{P} 2$. For instance, the following interplanar distances were reduced: $\mathrm{d}_{001}{ }^{*}$ from 1.220 to $0.945 \mathrm{~nm}, \mathrm{~d}_{001}$ from 0.642 to $0.627 \mathrm{~nm}, \mathrm{~d}_{002}$ from 0.318 to $0.314 \mathrm{~nm}$, and $\mathrm{d}_{003}$ from 0.214 to $0.213 \mathrm{~nm}$. This effect was reached due to the extraction of water molecules contained in three-layer packages. The process of water extraction belongs to the second endothermic effect that takes place in resistance heating in the temperature range between 560 and $680{ }^{\circ} \mathrm{C}$ [10]. At the same time, the number of water molecules trapped between basal lattice layers was also reduced. This effect was more significant for the humid environment (sample P3), as it

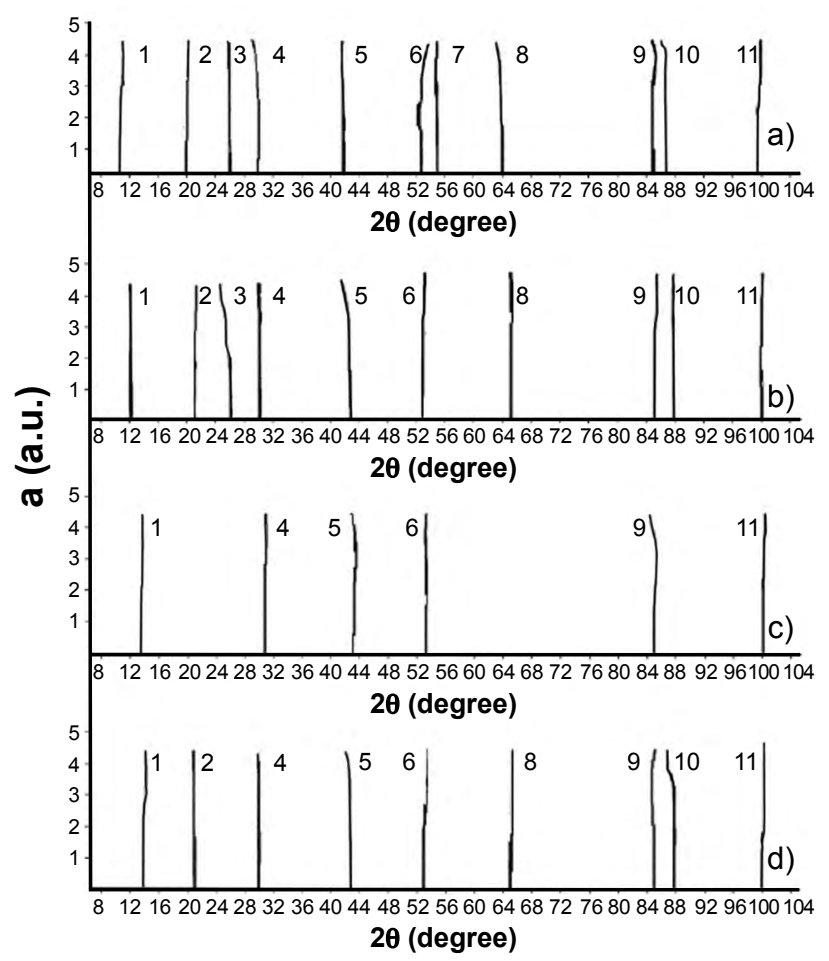

Figure 2: Skeleton of X-ray diffractogram of the samples: a) P0; b) P1; c) P2; and d) P3.

[Figura 2: Esqueleto de difratograma de raios $X$ das amostras: a) $P 0$; b) $\mathrm{P1}$; c) P2; e d) P3.] 
Table III - Structural changes in the crystal structure of montmorillonite due to the influence of microwave radiation.

[Tabela III - Alterações estruturais na estrutura cristalina da montmorilonita devido à influência da radiação de micro-ondas.]

\begin{tabular}{|c|c|c|c|c|c|c|c|c|c|}
\hline \multirow{2}{*}{ Line No. } & \multicolumn{4}{|c|}{$\mathrm{d}_{\mathrm{hkl}}(\mathrm{nm})$} & \multicolumn{4}{|c|}{ I $(\%)$} & \multirow{2}{*}{ hkl } \\
\hline & $\mathrm{P} 0$ & $\mathrm{P} 1$ & $\mathrm{P} 2$ & P3* & $\mathrm{P} 0$ & $\mathrm{P} 1$ & $\mathrm{P} 2$ & $\mathrm{P} 3^{*}$ & \\
\hline 1 & 1.220 & 1.080 & 0.945 & 0.940 & 100 & 80 & 70 & 70 & $001^{*}$ \\
\hline 2 & 0.642 & 0.634 & 0.627 & 0.634 & 40 & 20 & 0 & 20 & 001 \\
\hline 3 & 0.507 & 0.505 & - & - & 20 & 10 & 0 & 0 & 100 \\
\hline 4 & 0.442 & 0.442 & 0.441 & 0.441 & 80 & 30 & 30 & 30 & 110,020 \\
\hline 5 & 0.318 & 0.315 & 0.314 & 0.315 & 60 & 40 & 20 & 30 & 002 \\
\hline 6 & 0.256 & 0.255 & 0.255 & 0.254 & 80 & 50 & 30 & 10 & 200,130 \\
\hline 7 & 0.247 & - & - & - & 40 & 0 & 0 & 0 & 210 \\
\hline 8 & 0.214 & 0.213 & - & 0.213 & 30 & 10 & 0 & 20 & 003 \\
\hline 9 & 0.169 & 0.169 & 0.169 & 0.169 & 70 & 30 & 20 & 30 & 300,222 \\
\hline 10 & 0.166 & 0.165 & - & 0.165 & 70 & 50 & 0 & 20 & 310,142 \\
\hline 11 & 0.150 & 0.149 & 0.149 & 0.149 & 80 & 50 & 10 & 20 & 060,213 \\
\hline
\end{tabular}

* - sample P3 had the interplanar distance $d_{001}{ }^{*}=1.410 \mathrm{~nm}$

resulted in stronger heating of structured fragments which was due to the bigger amount of water molecules.

Diffractograms of all four samples presented in Fig. 1 showed that two samples demonstrated the reduction of diffraction peak intensity with the rise of the heating temperature (Figs. 1b and 1c). Crystal water extraction occurred stepwise. The sample P2 showed a continuous realization of the next step of montmorillonite lattice amorphicity. A similar degree of montmorillonite lattice destruction was observed in the interval from 800 to $900^{\circ} \mathrm{C}$ and it corresponded to the third endothermic effect. Approximately $40 \%$ of the original montmorillonite lattice volume was preserved in the sample P3. According to [18], this effect may manifest itself further in a reduction of endothermic effects with a shift toward the higher temperature region. According to the contemporary view [16], centers of hexagonal rings of water and centers of hexagonal rings of hydrogen in bonded silicon tetrahedra that are free from exchange cations are filled with water in the high hydration regime. Those layers are composed of densely packed $\mathrm{H}_{2} \mathrm{O}$ molecules, which cause the biggest expansion of structure layers and increase of interplanar distances. Expansion and contraction that takes place in a plane parallel to the basal plane may occur stepwise with the step size comparable with the radius of a water molecule $(0.138 \mathrm{~nm})$. In the low hydration regime, expansion corresponds to one or two monomolecular layers. Dynamic of interplanar distances (Fig. 2) and changes of intensity of peak No. 10 (Table III) was of special interest, as it should be treated as an index representing an amount of divalent cations trapped inside octahedra in silicon-oxygen packets. If the distance $\mathrm{d}_{060} \leq 0.150 \mathrm{~nm}$, then one can consider the cations to be trivalent and occupying octahedra in accordance with the corundum rules: occupied octahedra are united into hexagonal rings and a third of octahedra remains unoccupied by cations.
In [19] it was established that in EPR spectra of clay samples (Fig. 3) the most part of signals is related with ions of $\mathrm{Fe}^{3+}$ contained in the samples. One part of the ions is isomorphically included in the mineral structure, the other enters in various micro and nano-inclusions. Spectra showed two distinct groups of signals: narrow lines in $\mathrm{g}$ $\sim 2.0$ region and wide lines in $\mathrm{g} \sim 4.3$ region. At $\mathrm{g} \approx 2.0$, lines of nature-occurring aluminosilicates were attributed to electron-hole centers of radiation naturally appearing due to isomorphic displacement of cations in the octahedral layer; those were O-centers which were the stabilizers of the displacement. In most cases, spectra of this region were superpositions of a few (from 2 to 5 ) lines generated by both electron and hole centers [20]. Lines in $\mathrm{g} \approx 4.3$ region were due either to $\mathrm{Fe}^{3+} \rightarrow \mathrm{Si}^{4+}$ displacement occurring at the side surfaces of the mineral particles or to $\mathrm{Fe}^{3+}$ ions in tetrahedral

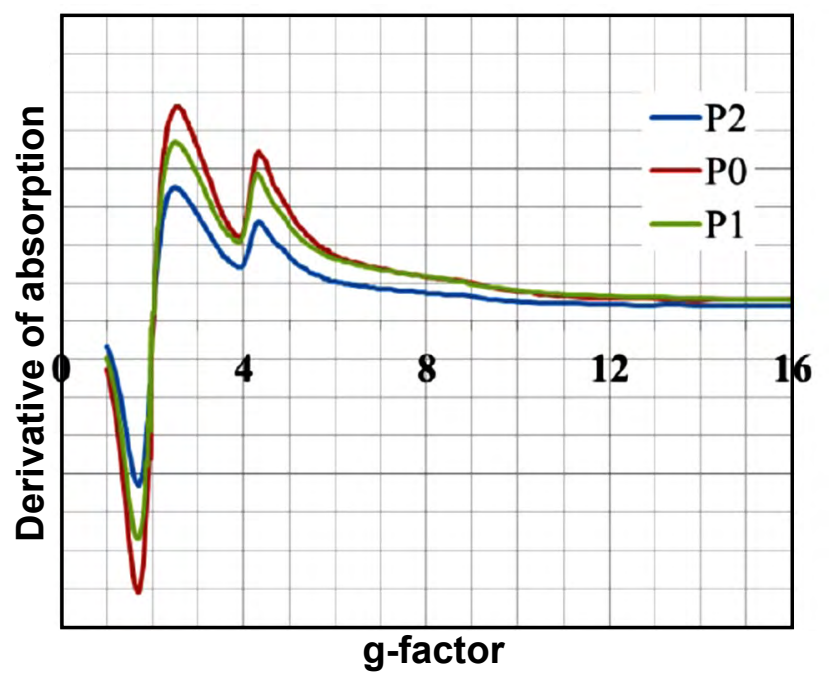

Figure 3: EPR spectra of samples P0, P1, and P2.

[Figura 3: Espectros de EPR das amostras PO, P1 e P2.] 
positions inside crystallites and in the basal planes. During microwave treatment of the samples, signals in both regions of $g$ were reduced consistently, which indicated degradation of the mineral structure similar to degradation during the traditional baking.

Microwaves influence on the dispersal system as the whole is a variety of local interactions taking place inside the system, which results in a microscopic effect and can be treated as a delayed or reoccurring effect manifesting itself during other external influences such as backing. This claim is indirectly supported by results in [21], where it was shown with the use of fractal parametrization that microwave radiation induces particle agglomeration. In these agglomeration processes, two phases can be defined which are described by the models of diffusion-controlled agglomeration (DCA, which describe the agglomeration growth due to inclusion of single dispersed particles) and kinetic-controlled agglomeration (KCA). At this spatial scale, agglomeration clusters are formed by merging of smaller clusters. Amorphous fragments of montmorillonite particles may serve as raw agglomerative material. Therefore structural changes induced by microwave radiation treatment affect the surface morphology of a sample. The relation between the microstructure and surface morphology is one of the most important issues of phase transitions of nature-occurring aluminosilicates.

\section{CONCLUSIONS}

Study of laws driving montmorillonite interaction with water is crucial for the understanding of structure formation processes and development of new functional materials. It was established that montmorillonite lattice was destroyed after microwave radiation treatment due to degradation processes. The degradation degree and the type of water extracted from the lattice were defined by the features of microwave radiation treatment: in the aerial environment, phase changes took place due to extraction of adsorbed interlayer water and the process was accompanied by destruction of approximately $50 \%$ of the montmorillonite lattice volume. The humid environment provided phase transitions that were accompanied by the second endothermic effect which results were chemical bond opening and destruction of approximately $70 \%$ of the montmorillonite crystal volume. In the ceramic mixed with water, approximately $40 \%$ of the original montmorillonite lattice sample was preserved. Therefore control over montmorillonite microwave radiation treatment provided an opportunity to induce delayed effects which manifest themselves in the formation of certain structures during traditional ceramic burning. These effects may reduce temperature and phase gradients due to reduction of endothermic effects and increase durability of the material due to creation of new nano-phases.

\section{REFERENCES}

[1] D.E. Clark, W.H. Sutton, Annu. Rev. Mater. Sci. 26 (1996) 299.

[2] S.V. Egorov, K.I. Rybakov, V.E. Semenov, Y.V. Bykov, O.N. Kanygina, E.B. Kulumbaev, V.M. Lelevkin, J. Mater. Sci. 42 (2007) 2097.

[3] H.J. Kitchen, S.R. Vallance, J.L. Kenned, N. Tapia-Ruiz, L. Carassiti, A. Harrison, A.G. Whittaker, T.D. Drysdale, S.W. Kingman, D.H. Modern. Chem. Rev. 114 (2014) 1170. [4] M.D. Patel, "Clay particle synthesis process", Patent Russian Fed. 2440295, Publ. B.I. 2 (2012).

[5] R.R. Menezes, P.M. Souto, R.H.G.A. Kiminami, in Sintering of ceramics - new emerging techniques, A. Lakshmanan (Ed.), Intech, Rijeka (2012) 3.

[6] R.M. Barrer, Zeolites and clay minerals as sorbents and molecular sieves, Acad. Press, London (1978).

[7] N. Worasith, S. Ninlaphurk, H. Mungpayaban, D. Wen, B.A. Goodman, in Clays and clay minerals: geological origin, mechanical properties and industrial applications, L.R. Wesley (Ed.), Nova Sci. Pub. (2014) 335.

[8] L.I. Belchinskaya, N.A. Khodosova, L.A. Bityutskay, Prot. Met. Phys. Chem. Surf. 45, 2 (2009) 203.

[9] S. Yapar, R.M. Sanchez, M. Emreol, P. Weidler, K. Emmerich, Clay Miner. 44 (2009), 267.

[10] L.I. Bel'chinskaya, K.A. Kozlov, A.V. Bondarenko, G.A. Petukhova, M.L. Gubkina, Russ. J. Appl. Chem. 81, 6 (2008) 965.

[11] N.F. Solodkiy, A.S. Shamrikov, V.M. Pogrebenkov, Ural mineral resources base for the ceramic, refractory and glass industry, Agraf Press, Tomsk (2009).

[12] A.G. Chetverikova, O.N. Kanygina, M.M. Filyak, E.S. Savinkova, Meas. Tech. 60 (2018) 1109.

[13] O.N. Kanygina, M.M. Filyak, A.G. Chetverikova, Inorg. Mater. 54, 9 (2018) 904.

[14] GOST 21216-2014, "Raw clay: test methods", Interstate standard, Standardinform, Moscow (2015).

[15] T.V. Kon'kova, M.B. Alekhina, A.P. Rysev, Russ. J. Phys. Chem. 87 (2013) 1762.

[16] L.I. Belchinskaya, N.A. Khodosova, L.A. Novikova, O.Yu. Strelnikova, F. Roessner, G.A. Petukhova, A.V. Zhabin, Prot. Met. Phys. Chem. Surf. 52, 4 (2016) 599.

[17] J.M. Gregoire, D. Dale, R.D. Bruce, Rev. Sci. Instrum. 82 (2011) 15105.

[18] I.A. Zhenzhurist, Inorg. Mater. 54, 9 (2018) 873.

[19] A.G. Chetverikova, O.N. Kanygina, in Proc. RussianJapan. Conf., Orenburg (2018) 65.

[20] N.S. Bortnikov, R.M. Mineeva, V.M. Novikov, B.F. Gorbachev, A.V. Speransky, Dokl. Earth Sci. 423, 2 (2008) 1488.

[21] A.G. Chetverikova, M.M. Filyak, O.N. Kanygina, Cerâmica 64, 371 (2018) 367.

(Rec. 04/04/2019, Rev. 24/06/2019, 15/07/2019, Ac. $17 / 07 / 2019)$ 